\title{
Effects on Electrical Distribution Networks of Dispersed Power Generation at High Levels of Connection Penetration
}

Paul Longrigg

July 1983

To be presented at the 18th IECEC

Orlando, Florida

August 1983

Prepared under Task No. 1421.00

WPA No. 149

Solar Energy Research Institute

A Division of Midwest Research Institute

1617 Cole Boulevard

Golden, Colorado 80401

Prepared for the

U.S. Department of Energy

Contract No. EG-77-C-01-4042 


\author{
Printed in the United States of America \\ Available from: \\ National Technical Information Service \\ U.S. Department of Commerce \\ 5285 Port Royal Road \\ Springfield, VA 22161 \\ Price: \\ Microfiche $\$ 4.50$ \\ Printed Copy $\$ 7.00$
}

\begin{abstract}
NOTICE
This report was prepared as an account of work sponsored by the United States Government. Neither the United States nor the United States Department of Energy, nor any of their employees, nor any of their contractors, subcontractors, or their employees, makes any warranty, express or implied, or assumes any legal liability or responsibility for the accuracy, completeness or usefulness of any information, apparatus, product or process disclosed, or represents that its use would not infringe privately owned rights.
\end{abstract}




\section{EFFECTS ON ELECTKICAL DISTRIBUTION NETWORKS OF DISPERSED POWER GENERATION AT HIGH LEVELS OF CONNECTION PENETRATION}

by

Paul Longrigg

Solar Energy Research Institute*

Golden, Colorado 80401 U.S.A. (303-231-1765)

\begin{abstract}
The advent and deployment of significant** levels of photovoltaic and wind energy generation in the spatially dispersed mode (i.e., residential and intermediate load centers) may have deleterious effects upon existing protective relay equipment and its time-current coordination on radial distribution circuits to which power conditioning equipment may be connected for power sell-back purposes.
\end{abstract}

The problems that may arise involve harmonic injection from power conditioning inverters that can af ect protective relays and cause excessive voltage and current from induced series and parallel resonances on feeders and connected passive equipment. Voltage regulation, var requirements, and consumer metering can also be affected by this type of dispersed generation.

The creation of "islands" of supply is also possible, particularly on rural supply systems.

This paper deals mainly with the effects of harmonics and short-circuit currents from wind energy conversion systems (WECS) and photovoltaic (PV) systems upon the operating characteristics of distribution networks and relays and other protective equipment designed to ensure the safety and supply integrity of electrical utility networks.

Traditionally, electrical supply networks have been desizned for one-way power flow-from generation to load, with a balance maintained between the two by means of automatic zeneration and load-irequency controls. Dispersed generation, from renewables like WECS or PV or from nonrenewable resources, can change traditional power flow. These changes must be dealt with effectively if renewable energy resources are to be integrated into the utility distribution system.

This paper gives insight into these problems and proposes some solutions.

\section{INTRODUCTION}

The addition of dispersed storage and generation (DSG) from PV and WECS resources to the electrical utility distribution network can pose technical problems for both the dispersed generator owner and the distribution network operator.

Instability and protection oroblems will occur, not as a function of the absolute power levels generated by DSG, but

* This work was supported by DOE under Contract No. EG-77-C-01-4042.

**Significant in this context is now generally agreed to mean greater than $50 \%$ of a feeder's minimum load cspacity rating. rather as a function of the DSG power output and the operating condition and power level of the transmission and distribution network into which the DSGs feed.

Incorporating renewable energy resources like wind and photovoltaics into the electricity distribution system introduces variables such as weather, area generation reserve, automatic generation control (ACC), and the inconsistency and diurnality of the solar resource.

Tecturiques and methodologies for effectively using nondepletable spatially dispersed generation have not yet been designed Present technology for the protection of distribution systems is not configured for the addition of dispersed gener ation.

Because a utility's investment in its distribution system of ten amounts to $40-60 \%$ of its plant and equipment inventory investment, it is imperative that new and ef fective distribution techniques be developed to successfully integrate all levels and types of DSG without imposing technical and economic burdens on any of the parties concerned.

Figure 1 shows a schematic of a typical iadial distribution feeder derived from a 12.47-kV substation bus. Ne'w energy technology generation will be added to this type of network in the future, both from intermediate load applications (i.e., shopping centers) and residential generation.

The quality of the power from DSG is of primary concern to the utility; voltage and frequency are particulerly important.

Utilities are of ten required by state law to meet voltage regulation requirements of $A$ NSI C $8+.1: 1977$, and var control is an important requirement.

The main effects upon voltage regulation arise irom the reversal of the usual direction of current flow under certain conditions. On a radial system serving only load, as shown in Fig. l, the power llow is unidirectional from source to load. But with the addition of dispersed generation, the direction of power flow will be dependent on the magnitude of the load, the magnitude of the dispersed generation, and their relative locations.

This seemingly simple phenomenon and departura from radiatity can have profound effects on distribution systern operations and planning and protection practices.

Safety considerations are also of prime importance where dispersed generation is concerned, and utilities will require positive and lockable open disconnects for DSGs.

Another factor that must be considered is the stability of supply criteria, because non-DSG consumers must not be adversely affected by the operation oi nearby DSGs. Loadfrequency control is the normal method of maintaining stability.

This is evident in Fig. 2 wherein the $27 / 59 / 8100$ relay gives on-site protection in this instance.

Power conditioning sustem (PCS) technology with renewable energy insiailations uses scatic soivi-state invercers ana i'eciiriers. The ivave cistortion and harmonic comoonents in the power waveform given out by these devices can have pro- 


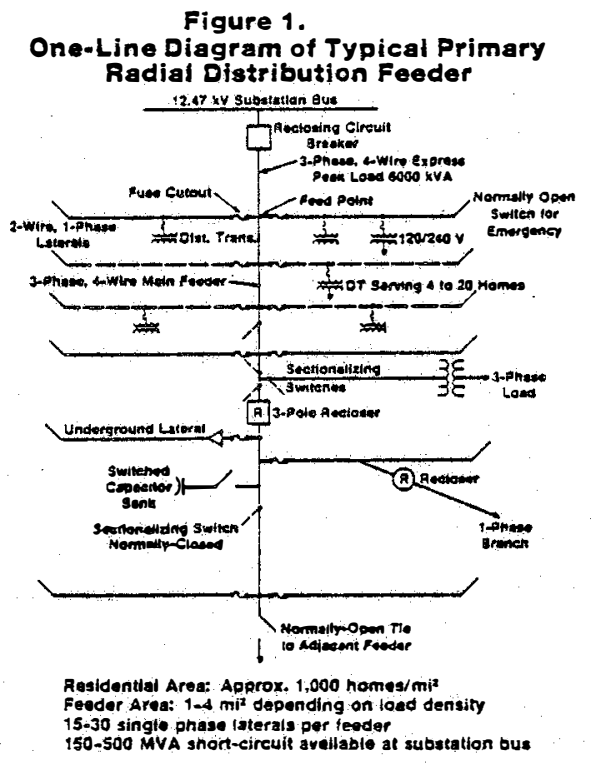

found effects upon protective relaying performance and coordination.

The effects of harmonics on both electromechanical and static relays must be fully appreciated and understood before DSGs can be effectively integrated into utility distribution systems.

From a utility transmission and distribution point of view, the impact of significant levels of DSG on base loads will need to be studied. This will be particularly pertinent to the rural electric utility which does not import much power. A baseloaded thermal plant that is excessively cycled to follow load can incur damage to water tubes and other equipment from thermal stress. Air pollution control equipment performance can also be compromised by boiler turn-down cycling.

Other steps that need to be taken before incorporating a DSG into a network (other than considering it negative ioad) are load flow, short-circuit current, and transient stability analyses.

These steps ivill not be dealt with in this paper, because a considerable body of literature already exists on these techniques using computer aided design ( $C A D$ ), albeit none deal specifically with DSG (1).

On-site storage at PV or WECS generation sites to ootimize the capacity factor where time-of-day rates may be used will obviously affect load flow and short-circuit current analysis, particularly at photovoltaic sites selling electricity back to the utility.

Effects of Waveform Distortion and Harmonics on Distribution Protection Equipment

System harmonics affect distribution protection relays in various ways leading to possible relay misoperation. Relays that depend on crest values and/or current-voltage zeros for their operation are obviously affected by harmonics. For instance, it is well known that the presence of excessive third harmonic currents may trip ground fault relays inappropriately. Third harmonic waveforms on the three phases of an electrical supply system are normally in phase with each other. When the three phases are joined in a wye connection, the harmonic urtents reiniorce aten other in ihe grounces neutrai ies.

Generaily the eifects of harmonics on protective relays are as iollows:
- Relays tend to operate slower with higher pick-up values rather than faster with lower pick-up values. This tendeney can of ten affect coordination, sensitivity, and selectivity.

- Static underfrequency relays are susceptible to substantial changes in operating characteristics.

- In many cases the changes in operating characteristics are relatively small over the moderate range of distortion expected from well-designed and engineered DSG installations.

- Standardized performance of relays from different manufacturers in the presence of wave distortion and harmonics is not available at this time.

- Based on harmonic content, operating torques of relays can of ten become reversed. This can have serious implications for directional overcurrent relaying using standard techniques.

- Operating times can vary widely as a function of frequency, i.e., harmonic mix in the metered quantity.

- Balanced beam impedance relays can exhibit both overreach and underreach in the presence of harmonics.

- Harmonics can impair the high-speed operation of differential relays and can exhibit complete restraint.

More specifically, the operating principle of a given relay or other protective device can have a major effect upon how the device responds to harmonics contained in the power waveform.

Electromechanical (E.M) relays tend to respond to the fundamental frequency component of a distorted wave, but this varies considerably among differing designs.

Fuse links tend to respond to the R.MS value, but large fuses of irregular shape, i.e., noncircular, have some sensitivity to high irequencies from skin and proximity eifects.

Selfcontained molced case circuit breakers tend to be more sensitive than fuses to distortion components.

Solid-state static relays (formerly sensitive to high frequency components) are now built with a variety of frequency and waveform responses that employ microprocessor techniques. Some relays, while insensitive to the frequency of an applied sine wave, may be sensitive to the waveiorm resulting from the presence of two or more frequencies. Thus, in a hostile harmonic environment, a protective system coordination plan based on $60-\mathrm{Hz}$ values may not provide the desired results if distortion ef fects are significant.

The effect of waveform distortion on other power equipment may be more significant that has been generally realized.

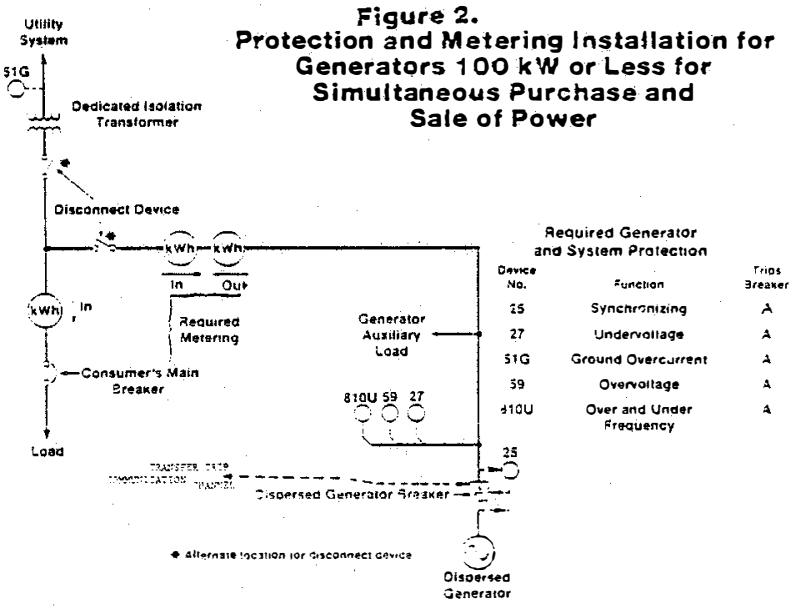


Capacitors are the only component for which Standards provide guidance with respect to wave distortion, and in many situations this is inadequate (see IEEE Standard 18:1968).

All large and closely spaced conductors and windings on magnetic cores are subject to skin and proximity effects. These effects result from a nonuniform current distribution within the conductor and cause an increase in the apparent impedance of the conductor. This is a function of frequency, conductor geometry, and harmonics typically found on feeders and can be significant. Such effects are not at present treated in the National Electric Code (NEC), but may have to be in the future as nonlinear loads and dispersed generation levels increase.

During fault conditions nonlinearity of resistance can result in wave distortion. Also during the fault conditions the load may substantially vanish and the wave distortion environment normally observed may not exist during the incidence of the fault. Back-up relays remote from the fault may carry appreciable load current (with its distortion) as well as the fault current which may or may not contain additional distortion.

At present each of these unknowns is treated by building more margin into the system than might be prudent or necessary, based on $60-\mathrm{Hz}$ data, thereby compromising safety.

With the addition of dispersed generation to the system, a further level of complication will be introduced. It is therefore desirable to better understand relay operating parameters in the presence of harmonics that are generated by dispersed generation power conditioners and nonlinear loads.

The efifects upon high impedance fault detection of wave distortion generated by DGSs must also be considered. These techniques employ some of the statistical properties of third harmonic power often generated by these hard-to-detect faults.

In their interconnection rules for DSG, one utility makes the following stipulation:

"At present no standards exist for the harmonic output of power inverters. If a customer using such a tevice for parallel generation is found to be interfering with other customers or the utility, or if standards are adopted in the future, the generating customer may be required to install filtering to bring the harmonic level of his inverter to an acceptable level."

The important words here are "found to be interfering with other customers or the utility."

At the present time there is no method whereby a quantitative determination of the effects of a particular customer's harmonic generation can be made. It is entirely possible now that a dispersed generating customer could be required to undergo considerable expense to install filters and deal with the attendant problems they can cause (2), when the additional equipment may not be needed because the electrical characteristics of the customer's power conditioner, the intertie point, and subsequent distribution system have mitigated or eliminated the effects of his particular harmonic generation upon the system. However, feeder harmonic simulation computer programs have been developed, which can be of immense help (3).

A further complication in this problem is that harmonic generation levels with some popular types of power conditioning equipment vary as a function of the time of day, solar irradiance, and wind velocity.

If the invertars in power conditioning opuioment spe gurrontsourced devices that may inject narmonic currents at the intertie point ceused by $\left[Z_{n}\right.$ voliage drops, it must be determined which way the harmonic currents will propagate.
They may propagate into the distribution system with its multitude of protective devices, which, as has already been stated, may be vulnerable to harmonics, or they may flow into residential loads.

Generally the impedances of paralleled household electrical appliances will be higher than the distribution transformer and its associated feeders. On this assumption the harmonic currents will propagate onto the distribution system. However, if residential loads should prove to be resonant at any particular harmonic, the situation could change radically (4).

The problem of harmonics can be further enhanced by having multiple dispersed generators with static inverter power conditioners feeding the same power transformer, as shown in Fig. 3. When harmonic power from the various equipment is in phase coherence, the power is additive.

Digital frequency relays are particularly sensitive to harmonics. Increased sensitivity is evident as harmonic content increases; this can result in uncoordinated load shedding during frequency excursions on the system. Some digital frequency relays tend to decrease in sensitivity as harmonics increase, and again this can lead to mistripping during frequency abnormalities (5).

Protective relays generally do not respond to any one identifiable parameter such as the RMS value of a primary quantity or the fundamental frequency of that quantity. As a related consideration, the performance of a relay to a range of single frequency inputs is not an indication of how that relay will respond to a composite distorted wave containing those frequencies. Superposition does not seem to apply in this situation. Multi-inout relays may be less predictajle than singleinput relays in the presence of wave jistortion. Furtinermore, relay response under distorted conditions may vary among relays having the same nominal frequency characteristics.

Response varies not only among different relay manufacturers, but also among different vintages of relays from the same manufacturer.

While there appears to be a myriad of problems associated with harmonics affecting the performance of distribution protection equipment, a first step in a solution to these problems is setting performance criteria relating to harmonic output from power conditioning equipment $(6,7)$.

Load flow analysis, at hurmonic irequensies, of a network containing dispersed generation will provide data on electrical characteristics of intertie points and rescnant situations

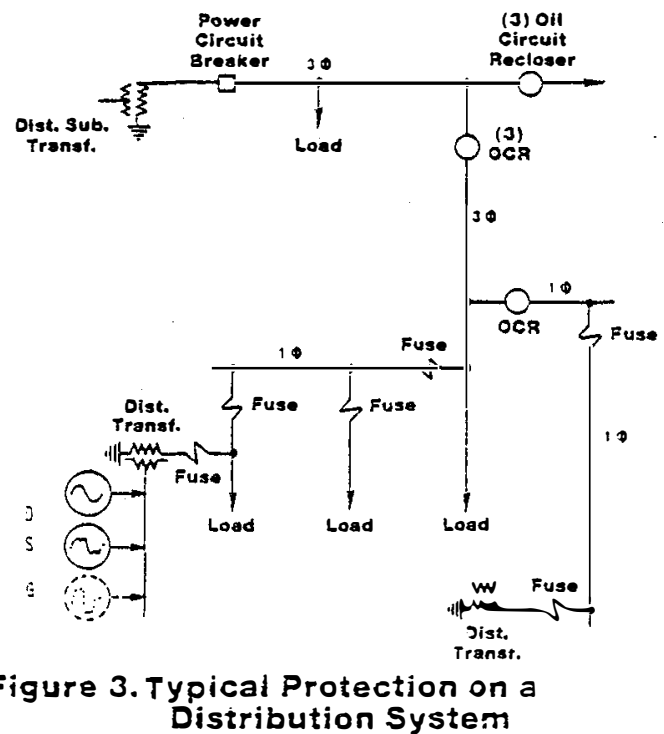


that could arise at the intertie point and beyond for a given level of dispersed generation and its harmonic output.

\section{GENERAL ASPECTS OF THE PROTECTION PRUBLEM ASSOCIATED WITH DISPERSED GENERATION}

\section{Short Circuits}

Short circuit currents on distribution circuits range from over 20,000 amperes to less than 1 ampere for high impedance single-phase-to-ground faults.

The maximum fault current can be controlled by system design, and most utilities set an upper limit of approximately $10 \mathrm{~K}$ amperes, so as not to exceed the rating of certain types of distribution line equipment. Maximum fault currents are limited by restricting substation transformer size and impedance by installing bus or circuit reactors, or by inserting reactance or resistance in the transformer neutral. On most circuits, the maximum value fault is a bolted, singlemphaseto-ground short at the substation. But since zero-sequence impedance of a distribution circuit is about three times the positive sequence value, a three-phase short circuit becomes the higher magnitude fault af ter moving down the line feeder a few thousand feet.

Minimum fault current magnitude cannot be controlled as the value is largely dependent upon fault resistance. These faults are the most difficult to detect and of ten constitute a dangerous situation. Wind and photovoltaics power conditioning units will be affected by this problem, particularly at low insolation levels and wind velocity.

Clearing times for short circuits on distribution circuits will vary widely, depending on fault magnitude and the type of protective equipment installed. In general on most well designed circuits, faults above 3000 amperes will be cleared in 0.1 seconds or less. Low-current faults frequently require clearing times of five to ten seconds or longer, and some very low level (but of ten dangerous) ground faults may not be cleared at all, except by manual disconnection.

Under certain utility operations it is possible for negative sequence currents to flow into a dispersed generator installation. This possibility and zero-sequence components should be avoided by appropriate isolation transformer connection.

Furthermore, fuse coordination could be a problem, primarily a function of the types of transformer connection usedgrounded wye/delta is the worst case because zero sequence current at the substation is reduced, causing desensitization of ground fault protective devices. Double sourge feeding a fault from DSG and main supply can result in I ${ }^{2}$ problems, of ten resulting in premature opening.

\section{Circuit Protection}

Figure 3 shows a typical distribution circuit with common protective devices. The circuit is normally supplied through a single power breaker located at the supply substation and is divided into various protection zones by automatic sectionalizing devices. These devices are carefully coordinated so that a fault in any section can be quickly isolated with minimum or no interruption in service to other nonfaulty parts of the system.

Of course, a fault occurring in the main trunk section near the source power circuit breaker will require that the entire circuit be interrupted. However, if automatic reclosing is employed, the duration of the outages caused by transient nonbolted faults in the affected zone will be limited to a brief interval, of ten considerably less than one second.

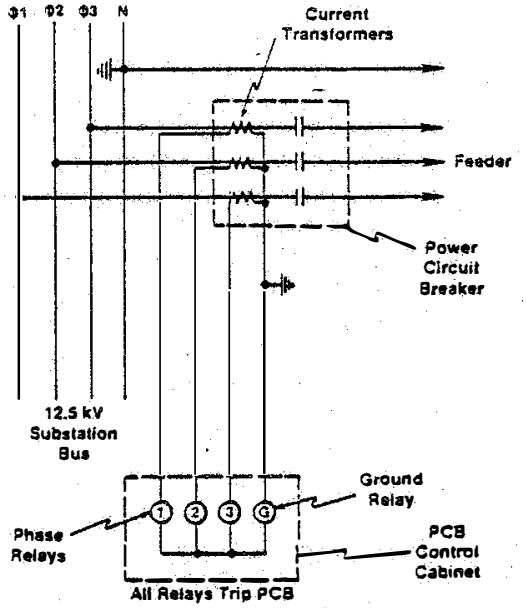

Figure 4. Protective Relay Configuration

Most electrical utilities depend on phase overcurrent and residually connected overcurrent relays, of ten referred to as a "ground" relay, to detect faults on the main trunk of distribution circuits. Such relays are of ten connected as shown in Fig. 4.

Phase relays are relatively insensitive to single-phase-toground faults because they must be set to operate above the maximum expected load current under emergency conditions. As a result, phase relay settings of 600 to 1200 amperes are not uncommon, particularly in urban areas. The ground relay receives the vector sum of the currents in the three phase (3p) relays, and both types must be coordinated with all other protective devices, including those associated with dispersed generation.

The sensitivity of phase and ground overcurrent relays is generally limited because they must be low enough to coordinate with all downstieam protective devices and high enough to prevent incorrect tripping due to large inrush currents that may occur during cold load pick-up.

Ground relays must also be set high enough to prevent accidental tripping on load imbalance, and this imbalance may be greatly increased upon the operation of a fuse or oil circuit recloser serving a single-phase transformer tap. Imbalances caused by the variability of solar dispersed generation merely complicate the matter.

Consider the time-current responses shown in Fig. 5 . If the largest recioser on a particuler circuit is represented by curve $A$, a ground relay set as shown in curve $B$ will properly coordinate with this recloser. However, operation of the recloser will cause a change in the residual load current as sensed and measured by the ground relay.

This may result in a current higher than the relay setting, and the entire circuit would be incorrectly tripped. To overcome this problem, it is frequently necessary to set ground relays as high as one half the setting on the phase relays; some companies have found it necessary to remove all residually connected relays from their distribution circuits because of this.

The detection of ground faults on a single-phase tap may be greatly improved if a fuse or a recloser is installed at the point where the tap is connected to the main line. This device will usually operate at a considerably lower fault current level than the relays at the station breaker. However, their sensitivity is still limited by the amount of load current that must be carried on the tap, and the fact that they must coordinate with the fuse protecting the largest transformer connected to the tan. 
Figure 5. Oil Circuit Recloser Characteristics

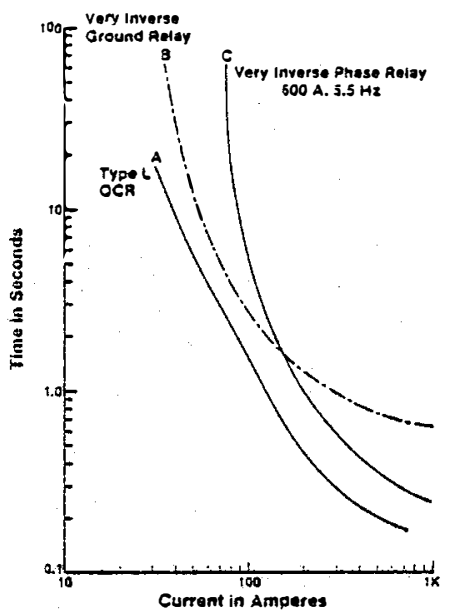

Protection may also be improved by providing properly coordinated protective devices on the various subbranches. Experience has shown, however, that even lightly fused subbranches may be subject to downed conductors that are not de-energized. This generally occurs when a high resistance at the point of fault has limited the ground fault current to a very few amperes. Note that the sensitivity of any overcurrent protective device will always be limited by the need to survive the heavy insush currents that will occur when feeder circuits have been de-energized for a long outage. Such currents have increased markedly in recent years, particularly with the increased use of home and commercial electric heating and cooling units (heat pumos) in many areas. Addition of dispersed generation into such circuits further complicates the coordination problems (see Appendix).

\section{Automatic Reclosing}

Operation of dispersed stcrage and generation (8) may be affected by the automatic reclosing schedule adopted by individual utilities for their distribution circuits.

Some utilities do not reclose the substation PCB af ter protective relay operations under any circumstances, but prefer to rely on supervisory control (SCADA) or manual restoration of service. Some utilities prefer one-time ultra-high-speed reclosing on all overhead circuits. Miost utilities, however, will employ multiple-shot reclosing for their distribution station breakers, as shown in Fig. At.

The initial reclosing can take 0.33 seconds or as many as 3 to 5 seconds. Then one or two additional time-delayed shots are progiammed on the PCB reclosing relay.

A typical reclosing schedule might be "instantaneous" followed by 16 seconds, then 60 seconds; or instantaneous, followed by 3 or 30 seconds, followed by 15 seconds.

In general automatic reclosing is not permitted on underground network systems because faults there tend to be predominantly bolted or permanent. In any event the protection aspects of DSG must be fully coordinated with all network switching philosophy.

Three-phase and single-phase oil circuit reclosers $(O C R)$ are widely used on overhead distribution lines. Most of these devices are set to provide "three-shots to lock-out"; that is, after a fault has been detected by an overcurrent sensing element, the recloser will open to de-energize the circuit and reclose af ter a short period. The sequence will be repeated a few more times unless the fault has been cleared. If the fault is "jermanent, "iie iecloser will remain upen arier ine iourth trip operation.
In recloser operations it is important that all associated DSGs liable to feed a fault are disconnected before the recloser commences it sequence, to avoid sustaining the arc. Restoration sequences, perhaps computer controlled, will be undertaken after the fault is cleared.

Unlike the current-limiting fuse, circuit breaker reclosing is not designed to limit equipment damage at the fault site, but to protect the continuity of power to the unfaulted remainder of the network.

\section{Protection Technique}

In presently used electric distribution systems, both overvoltage and overcurrent protection is required. Overcurrent protection is provided by the time-current coordination of fuses, sectionalizers, and reclosers that are used to sense and isolate fault currents with minimal interruption to consumers, while providing maximum equipment protection. Under some conditions these two requirements are mutually exclusive.

Overcurrent sensing can sometimes be difficult on large interconnected networks, where current surges are frequent and felt, to some degree, throughout the parallel network.

Most distribution networks in use today are radial in their electrical configuration, and overcurrent protection is provided by unidirectional time-current relays that are not generally designed to protect distribution systems having bidirectional power flow. Overvoltage protection resulting from surges produced by lightning, line-switching transients, ferroresonance, etc. can be provided by various surge arrestors.

These types of protection can be affected by dispersed solar generation since power output can vary due to weather variabilities.

Start-up and cold load pick-up causing phase imbalances can also induce overvoltage transients on the distribution network that may be sensed. Furthermore, zero sequence resonance can occur due to excitation of neutral capacitor banks during faults, which causes overvoltages to be incident. Ferroresonance can also be a problem with 3D connected DSGs.

Protection of a distribution system against abnormal operating conditions means that the protection equipment must be configured to be optimally sensitive and selective and to operate at a speed that detects and isolates abnormal current in a time frame that will not cause damage to distribution equipment and will not unduly interrupt service to consumers. This is normally done by correct cocrdination of protection equipment.

However, the introduction of dispersed generation into the network necessitates a reevaluation of current techniques, primarily because the dispersed generation may change current flow from unidirectional to bidirectional, and fault current magnitudes will no longer decrease down the feeder.

One positive attribute of dispersed generation, however, may be its support of voltage on long rural lines, instead of the current method of switched capacitors or employing voltage regulator equipment.

The var support on lines is also possible by correctly phasing power conditioning units, when not in use at solar dispersed generation sites, particularly on feeders in rural areas.

A particular concern is how the effects of dispersed soiar generation with its time variant parameters may affect present time-current coordination derived from steady-state load flow and short-circuit analyses.

The concept of negative lcad has been advanced for disoatch oi nonsolar congenterdion di iow hevels ut hetivork penerration and is oeing used eifectively oy utiuties at present. 
However, there is some doubt about the veracity of the negative load concept at high levels of penetration, and of dynamic optimization of protection coordination.

If a dispersed generator is not correctly coordinated with existing distribution protection, the dispersed generator may continue to energize a nonbolted fault.

If a dispersed generator contributes significantly to fault current, this may clear a fuse or cause a recloser to operate in an uncoordinated way, if selectivity or sensitivity has been affected.

Note that complete selectivity among protective devices is seldom possible, and the addition of dispersed generation will further complicate the issue. After loading and protection requirements have been satisfied, compromises usually have to be made in the coordination process to achieve optimum selectivity.

A further area of concern is automatic reclosing onto a dispersed generator. Such automatic reclosing is of ten employed on distribution networks experiencing a high level of nonbolted faults from lightning strokes and feeder wind lash. This type of reclosing could damage the dispersed generator or interrupt commutating switching power to line-commutated inverter equipment.

During the short period of recleser operation, synchronism with a non-line-dependent device could be lost, and reclosing out of synchronization could damage a DSG from heavy in rush currents caused by out-of-phase voltages. If there is sufficient energy storage in the commutation circuitry of line dependent inverter equipment, short-term isolated operation is possible for a single DSG, and perhaps longer-term operation for multiple dispersed generators disconnected from the primary supply (i.e., interactive operation between dispersed generators on the same feeder section).

In both instances a dangerous situation can arise for linesmen working with bare hands, when frequency and/or voltage tolerances of relays allow an "island" to exist even briefly.

This could be considered the equivalent of wide acting governors on electromagnetic rotating machinery. Low-power, single-phase dispersed generation intertied to three-phase distribution systems can cause unbalanced conditions to occur, both during cold load pick-up and relaying operations. If the syster. becomes heavily imbalanced, negative sequence currents will fow that could actuate negative sequence re lays or damage electromechanical equipment also connected to the line.

This could prove a particularly serious problem on rural lines that supply milking equipment. As little as one volt between neutral and ground can cause problems.

For viable and effective utilization and control of dispersed generation, it is vital that correct coordination be obtained. Properly functioning coordination ensures that when a problem occurs the right breaker opens to isolate it. Coordination also ensures that breakers do not close when doing so would cause damage or result in an accident.

\section{Commutation Faults}

"Commutation errors" in power conditioning equipment using solid-state devices like thyristors are not uncommon. These errors are of ten induced by line transients, which either short or open the solid-state switching device. In either event these errors can have serious consequences for a distribution system from dispersed generation without an isolating transformer, when this is allowed by local codes.

Protection equipment normally clears sine wave energy or a waveform with some degree of asymmetry; it is not designed to clear de faults, which commutation errors will induce.
With isolation this condition is important only to the dispersed generator owner. However, isolation transformers are expensive and inefficient, and it is possible, as a consequence, that they will either not be installed (where local electrical codes and regulations allow this) or some substitute method might be used in lieu of the isolation transformer.

One substitute method involves the use of a circuit breaker at the output terminals of a power conditioner, actuated by a Hall effect de switch when a commutation error occurs.

When contacts have been closed for a long time, they have a propensity not to open in a nonpreventative maintenance environment. The actuation time of the combined breaker and de sensor could allow a period of time when dc is injected onto the distribution transformer. This can have significant effects upon the harmonic seneration capabilities of the transformer by causing magnetic saturation. Such harmonics may cause fuses to clear inadvertently, thereby affecting service to other customers.

Mitigation of these deleterious effects calls for very fast acting breakers, probably of the solid state variety ( 9 ).

\section{Directional Overcurrent Relaying}

Traditional directional overcurrent relaying relies on positive-sequence power flows toward a fault and negativesequence power flows away from it.

The actuating torque in a directional device uses this relationship. In the presence of zero-sequence power, perhaps caused by phase imbalance of dispersed generation undergoing its diurnal cycle, a mistrip could occur. Techniques will have to be developed to eliminate or mitigate this effect.

\section{Directional Control}

Reversal of power direction in a normal radially fed system can occur on the clearing of a fault. Such momentary power reversal can cause false tripping of slow speed directional overcurrent relays if means are not taken to prevent it. This is termed directional control, and the techniques presently used need to be examined in light of the known and anticipated effects of dispersed generation on the system.

\section{Conventional Directional Overcurrent Devices}

In a loop or ring-main as shown in Fig. 6, protective relays with an added directional property are required.

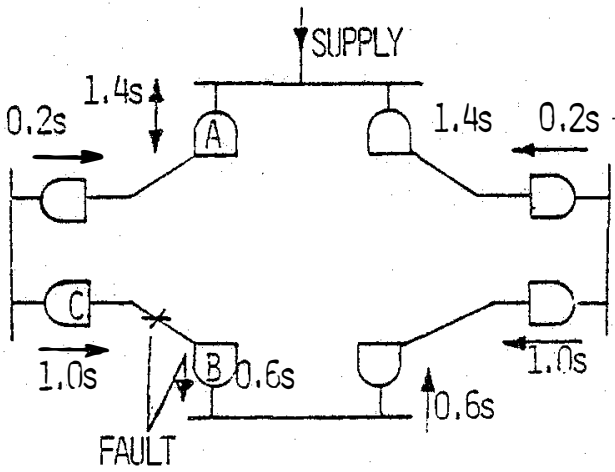

FIGLRE 6. APPLICATION OF MIRECTIO!ALL RELAYS TO A. LCOP MET:ORK

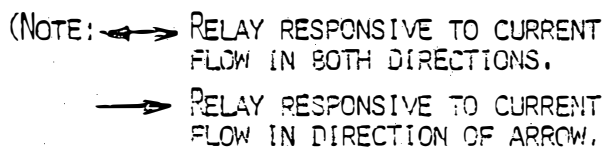


For a typical system as shown in Fig. 6, directional and nondirectional overcurrent relays have time lags for a given fault current as shown. Current feeds into the fault at the location indicated from both directions, and the first relay to operate is at $B(0.6 \mathrm{~s})$. Note that a similar situation could exist on a radial distribution system with dispersed generation if a fault were fed from two directions or where a distribution system can be backfed.

The fault now occurs along route $A C B$ only, and the next relay at $C$ ( $l \mathrm{~s}$ ) operates and completely isolates the fault from the rest of the system. Assuming a circuit breaker operating time of $0.3 \mathrm{~s}$, complete selectivity is obtained at any fault position.

Directional relays are vital elements in interconnected systems to control the flow of power. They are usually set to detect a value of current, but since current flows in both directions in an ac circuit, they detect direction in terms of power llow.

Two instrument transformers are needed-a current transformer. (CT) to measure magnitude, and a potential transformer (VT) to polarize the relay to read in one direction only. A directional relay is needed to ensure that power does not flow into interconnected generator/alternator se ts ensuring: they do not "motor."

\section{Microprocessor-Based Directional Overcurrent Relay}

In the circuit schematic shown in Fig. 7, a small step-up transformer $\mathrm{Tl}$ is connected across a very low series resistance such as the internal resistance of a ground fault interrupter, fuse, or circuit breaker, which provides a voltage proportional to load current 1.

This current signal is amplified and phase detected in a phase-sensitive rectifier, which provides phase information to the microprocessor. This phase information is derived from the $I^{2} R$ drop across the resistor when compared to a reference level. Direction of power flow through the resistor can then be determined. Concurrently, the current magnitude signal is read by an analog-to-digital converter ( $A / D$ ) whenever it receives a sample-and-hold pulse.

The sample-and-hold ( $\mathrm{S} \& \mathrm{H})$ pulse is derived from the line voltage through the step-down transformer $\mathrm{T} 2$. The output of this transformer is shif ted by $90^{\circ}$, clipped, and dif ferentiated to provide a narrow width $S \& H$ pulse that occurs at the peak of the current sine wave, assuming a unity power load. The $A / D$ unit reads a signal proportional to I $\cos \theta$, where $\theta$ is the load power angle. Assuming ressonably sinusoidal currents and voltages, this signal is proportional to power for a given line voltage.

The digital signals are input to a microprocessor, and processed parameters can be displayed on a readout. Load powers are compared with limits in the microprocessor hardware; which can be dynamically updated as necessary. Outof-limits power levels can give annunciated alarms, initiate breaker trip routines, and monitor for some established reconnection criteria.

Although only a single-phase representation is shown in Fig. 7, three-phase versions could be implemented for deployment on feeder systems and intermediate/central station solar renewable enersy applications.

This technology is available today, at a price that is consonant with the deployment of digital systems in general.

\section{Distributed Intelligence on Feeders Containing Disoersed} Jenerarion

For the effective deployment of distributed energy oroduction, power distribution systems will need improved control capabilities.
Figure 7.

Basic Schematic of Directional Overcurrent Relay Using a Microprocessor

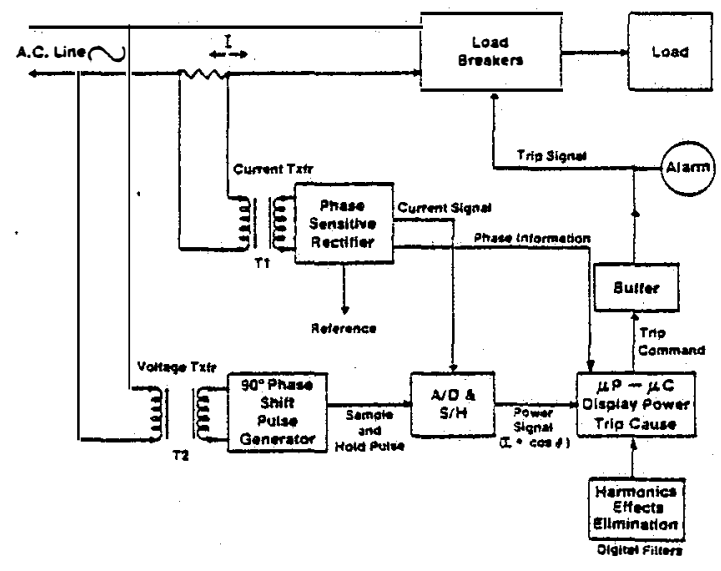

Current thinking is that high density digital logic in the form of packaged microprocessors and computers will meet the need. However, it should be remembered that while the cost of hardware chips in this rapidly advancing technology have been reduced drastically, the costs of program sof tware have not followed suit. In fact, they have risen because of the labor intensity of the task.

These factors will certainly be important in the deployment and implementation of so-called microprocessor-based distributed intelligence; one reason is that new generalized control algorithms will have to be designed and developed. This is a sizable task given the real-time operating environment.

Microprocessor-based circuit breakers and other components of the kind described above could be employed in the pole top distributed intelligence and control role and at a local level interacting with a host or master computer at substation.

A great deal is being learned about real-time control of industrial plant and equipment and transmission of data in the telecommunications industry, which will help in using microprocessor techniques in the DSG control role.

The advent of load management and remote metering using duplex communication channels in the 150 and $900 \mathrm{MHz}$ radio frequency bands will also be valuable in DSG communications and control.

The electrical environment in the distributed control role is liable to be severe for the low-level logic that is found within microprocessors. Consequently it may be necessasy to have to develop a line of noise immune microprocessor logic especially tailored to the utility distribution electromagnetic environment found in substations and pole tops, as was necessary for industrial digital computer control.

\section{COMMUNICATIONS FOR DISTRIBUTION AUTOMATION}

With continued study into the integration of DSGs into utility networks, one fact is becoming abundantly clear: for DSG deployment and use to be successful, vastly improved communications systems will be required ( 10$)$.

Traditional communications methods for electrical supply have involved an amalgam of radio, telephone, and power line communications. These methods, while always in need of improvement, have met the needs of electricity suppliers and their customers.

With the advent of cogeneration and cenewaole energy iecnnologies, however, distribution communicgtion requirements as an integration issue has been identified as singularly imoortant for distribution automation. 
A great deal of this attention derives from the communications experiments undertaken by DOE, EPRI, and others in the load management area, and in particular communications for remote meter reading. However, communications requirements for distribution automation (control, protection, and status monitoring) will be significantly different than those required for remote meter reading and direct load control. These requirements will need to be addressed in the near future as utilities evaluate alternative communication technologies, particularly with the $900-\mathrm{MHz}$ radio frequency band soon to be available.

Distribution automation will require two-way communication for such functions as data acquisition, control, and confirmation of status. Communication requirements will be expressed in terms of data rate, reliability, throughput, and coordination. These requirements will vary by function and will vary between normal and emergency operating conditions. Should a communication channel also be shared with other functions like load switching control or remote meter reading, then the bandwidth and protocol requirements will increase. Furthermore, communication requirements will vary with the individual utility applications, due to substation/ f eeder design and operation.

The communication system required in a fully implemented distribution automation system will have four major links:

- feeder communications from feeder remote units

- modules within the substation

- communications between the substation and distribution dispatch center

- communications between the distribution dispatch center and energy management control.

Within this structure, each of the four links will have its own set of requirements for various functions. Note, however, that the more decentralized or distributed the processing is, the fewer are the communication requirements.

A ïrst step in selecting a communication channel at each level should begin with a complete specification of the functional requirements, as well as the functional role of each module in the automation system. Communications systems will need to be structured in a vertical hierarchy, otherwise an infinite network at each level could cause technical and economic problems. Once the complete functional requirements for the communication channel are established, an evaluation of the options available for two-way (duplex) channels may be undertaken, balancing technical and economic factors.

The differing application requirements of individual utilities will most likely result in several different technologies being deployed for the substation-feeder link. This proliferetion of technologies could lead to duplication of effort if standards are not prepared and implemented. Should one communication technology dominate in the future, the automation system should accommodate the communication medium, but the technology will be primarily driven by the communication medium most readily available at the least cost.

Perhaps the most promising new communication technology to emerge recently is that of single-mode optical fibers transmitting coherent light along considerable distances to sensitive photodiodes.

This technology is being extensively deployed by the telecommunications industry in the United States, and electric utilities in Japan have used fiber ootics for communication and control since 1975 (11).

Communications technology beyond that presently emcloyed or Sudervisory Sontrol and Data AnalysisiRemote Torminal Unit sustems will have to be evolved for disoersed jonera- tion. A positive step in this direction has been taken in the "PKOBE" project at the La Grange Substation of Commonwealth Edison at Chicago, IL (12). A schematic of the experimental work done on the "PROBE" projeet is shown in Fig. 8.

The primary purpose of this pilot project was to utilize the low-cost potential of digital technology by eliminating redundant wiring, sensors, and other components. This integrated approach required a fundamental examination and close look at existing methods of power distribution and associated communication systems.

\section{The "PROBE" project sought to}

- define distribution automation functions when implemented digitally

- develop data bases for the automation of substation and feeders

- demonstrate the viability of digital automation on electric distribution systems.

The prototype system consisted of two microprocessors coupled with distributed high-speed data acquisition and processing units. A total of eight units with microprocessors and communications interfacing for remote control were mounted on power distribution poles on selected feeders, as shown in Fig. 8. The communications for feeder control was done mainly by radio, but a power line carrier was used to verify radio data.

Base station computer A was used to collect and process substation data, maintain the data base, and use derived algorithms for automatic control. Computer B was used primarily for coordinating the system and its communication channels and executing control algorithms on sectionalizing and switching of feeders, together with voltage regulation and reactive (var) power control.

The instrumentation system used auxiliary current and voltage transformers for power sensing and multiplex signal switching for sampling each parameter about twenty times for each $60-\mathrm{Hz}$ cycle. Sampling times of distribution system parameters are often critical because breaker switching times have a direct bearing on system stability, and signal multiplexing must have a wide range of performance. Computers operating in this type of real-time environment usually require sophisticated interrupt structures, and much work needs to be done in this area.

Computer A, with input from a high-speed data processing unit, calculates the parameters normally measured by on-site instrumentation (RMS values of current and voltage and other data for the total integration of control functions).

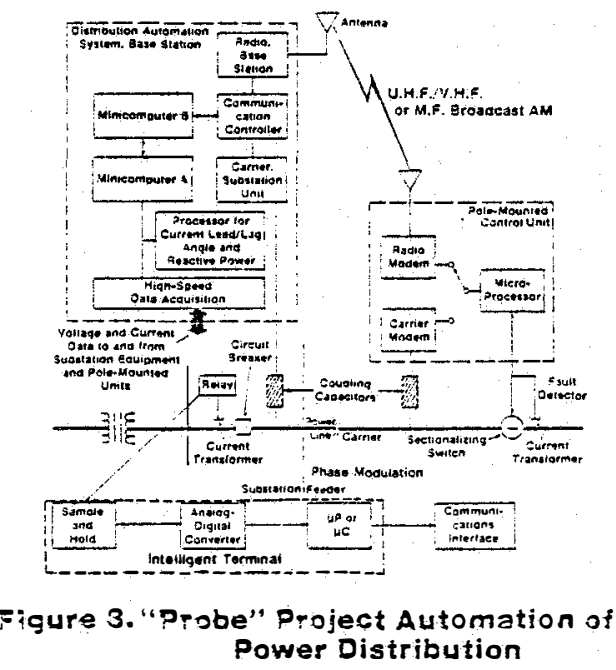


Because of real-time speed of processing requirements, hardwired multipliers were used instead of program multiply routines, which are of ten slow in execution. A separate microprocessor at the substation controlled communications to and from the pole-mounted units in the field. This processor also coordinated communication protocols for fault detection and breaker switching.

Array processor type computers might be needed in some instances at the substation because of the large amounts of data that are input.

The radio frequency link shown in Fig. 8 was in the $150-\mathrm{MHHz}$ com mercial radio band.

One of the primary attributes of distributed microprocessorbased coinmunications and control is the inherent capability to dynamically uodate the power distribution equipment configuration for optimum load flow and restoration of service following section outage. A flow diagram control algorithm for this is shown in Fig. 9.

Such dynamic reconfiguration procedures would allow optimum use of equipment under fault conditions, where (as always) minimum disturbance to nonfaulted parts of the network is required.

The reconfiguration menu in the logic is continuously updated by input from remote terminals about their status. Apart from distribution automation, this continuously refreshed data can also be used for dispatch purposes, and some level of on-line load flow analysis could be done to adjust timecurrent coordination of relays and breakers as a function of dispersed generation status on the system (such as shortcircuit current capability for network protection if and when faults occur).

As noted previously, communication media availability will drive the technology to some extent. This is already occur' ring for excessive use of the radio frequency spectrum, coupled with the expense of dedicated telephone lines, is driving the utilities to seek other communication media; hence the interest in fiber optics.

If îber optic communications can give the high reliability needed for DSG deployment, that technology could enhance the use of dispersed power.

\section{On-Site Battery Storage}

The question of on-site (local) energy storage-batteries-at wind and photovoltaic generation sites, is a complicated one (8).
Commercially available lead-acid batteries are expensive because of their limited charge-discharge life-cycle. As a consequence, where a dispersed generator has capacity in excess of load, the excess energy can be sold to the utility by interconnecting the DSG's output with the utility grid under a PURPA arrangement.

However, the availability of energy at a solar site may not coincide with the peak load of the utility it is connected to. On a purely technical basis this would appear to merit some sort of storage so that excess capacity may be sold back to the utility at its peak load time.

On an economic basis the issue is not clear. Buy-back rates and time zone wheeling are clearly parameters that affect: energy storage.

\section{CONCLUSIONS}

Whenever dispersed generation is connected to a distribution system at a power level sufficient to cause stability problems, it becomes important that load flow, fault current, and transient stability analyses be carried out prior to connection.

These analyses are needed to determine relay coordination settings under both static and dynamic dispersed generation conditions. They will also ensure that nongenerating customers are not affected by the on-site generation of their neighbors. Preferential locations and stability factors for dispersed generation can also be derived from these analyses.

Furthermore, fuse saving practices are not effective when used with instantaneous fault detection for DSGs. Delayed reclosing should allow time for DSG disconnection. Fusing the high side of distribution transformers with DSGs in parallel may be a questionable practice because of zero-sequence current how in the load.

The sensitivity settings of older style relays of ten preclude the detection of faults on adjacent feeders, thereby making selective fault removal difficult. But the use of distributed digital logic may be of help here. Overcurrent relaying of DSG can be made a reliable indicator of faults, particularly if variable sensitivity can be obtained by the use of computer techniques as outlined in Figs. 8 and 9.

High short-circuit currents can be supplied by synchronous generators that are sometimes used in wind energy conversion systems. But short-circuit time decrement under fault conditions at the output port must still be determined to obtain correct coordination.

Phase imbalance due to fuse clearing and cold load pick-up must be guarded against with solar DSG.

Resonances from harmonic generation could cause problems. Complete electrical characterization of anticipated tie points and remedial measures, if needed, are therefore recommended.

Safety of linesmen is of primary concern in the deployment of DSG. In this respect there seems to be little that can substitute for a brief on-site inspection of lock-open DSG disconnects. A communication system might conceivably act as a substitute, but its reliability, and therefore its cost would be inordinately high. But the concept does present a challenge.

The integration of dispersed and distributed power generation into the existing electrical grid system will not be a trivial matter. It will, however, be an evolving one, and as mistakes are made improvements will take place. The learning curve will be climbed with time, and the ratio of success to failure will be one of the arbiters of marketplace acceptance.

The use of new and exotic technology should be viewed with extreme caution. Ot ten the newness and noproven tiaid as- 
pects of the technology can cause problems with cost and reliability. However, new technology should not be excluded from consideration simply because it is new. Rather, thorough and exhaustive trials and tests of new technologies should be made to gauge their effectiveness, cost, and above all, RELIABILITY.

\section{REFERENCES}

1. "Primary Feeder Analysis: Computer-Aided Distribution Planning and Design System" Descriptive Bulletin 52-325. Westinghouse Electric Corp. Jan. 1982.

2. Longrigg, P. "DC to AC Inverters for Photovoltaics." Solar Cells. Vol. 6, 1982. p. 343.

3. Dugan, R. C. et al. "Harmonics and Reactive Power from Line-Commital Inverters in Proposed P.V. Sub divisions." IEEE/PES 1983 Winter Power. No. 83-WM-137-7. New York: Mcgraw-Edison Co.

4. Fuchs, E. F. "Impact of Harmonics on Home Appliances." June 1981. DOE RA-50150-9.

5. Jost, F. A. et al. "Effects of System Harmonics on Power System Relays." Canadian Electric Assoc. Conf. Mar. 1974.

6. Baitch, T. L. "Network Harmonic Limits, Australian Standard; Specifying." A. S. 2279: 1979. IEEE/IAS, Vol. 1A-18. No. 3. 260-267. Mlay/June 1982.

7. Institute of Electrical and Electronics Engineers. Standard 519. New York. 1981.

8. Nakano, So et al. "A 2-kW Photovoltaic Power Generating System using a-Si Solar Cells." 1982. IEEE. Photovoltaic Specialists Conf.

9. ASEA Current relay data. Type RXIC $12010 \mathrm{E} .1983$.

10. Mosian, R. "Distribution Automation \& Control" General Electric Co. DOE Conf. on Research Needs for Effective Integration of New Energy Technologies into the Electric Utility. St. Mlichaels, .MID. July 1982.

11. Aoki, F. et al. "Optical Fiber Communications for Electric Power Companies in Japan." Proc. IEEE. Vol. 68, No. 10. Oct. 1980.

12. Bunch, J. B. et al. "PROBE and Its Implications for Automated Distribution Systems." Proc. Am. Pwr. Conf. Vol. 43. Apr. 1981.

A1. "Distribution System Protection Manual" Bulletin No. 71022. McGraw-Edison Co. Power Systems Division.

\section{ACKNOWLEDGEMENTS}

The author would like to acknowledge the following people for help in the review and critique of this paper: John Stevens, Tom Key, and Gary Jones, Sandia National Laboratory, Albuquerque, NM; Paul Russel, Arizona State University, Tempe, AZ; David Waddington, SERI, Golden, CO; Tom Rizy, Oak Ridge National Laboratory, Oak Ridge, TN; Jeff Rumbaugh, U.S. Department of Energy.
APPENDIX.

OVERCURRENT (FUSE-RELAY) COORDINATION ON A DISTRIBUTION CIRCUIT CONTAINING DISPERSED

GENERATION

A coordination example of recloser and fuse links, with added dispersed generation from wind or photovoltaic, is shown in Fig. Al.

Available fault currents at application and points are denoted in circles. Maximum fault current is shown in the upper hemisphere, while maximum fault current is shown in the lower.

Fault current and load flow analysis will indicate fault current magnitudes for all feeder excitation.

A three-phase (30) recloser $R l$ is located at the substation secondary. Fuse link groups $\mathrm{F} 1$ and $\mathrm{F} 2$ are located at or near sectionalizing point S1.

The fuses and recloser must be time-current coordinated with and without the dispersed generation so that for any faults that occur between points Fl/El\&2, the feeders are first isterrupted by the recloser on its fast curve, and then if the fault(s) persists, by the appropriate fuse group. Furthermore, the recloser should be capable of interrupting any faults that may occur between the transtormer secondary and the sectionalizing point Sl.

For the transformer voltage and current depicted, a recloser with an interrupting rating of $\$ 000$ amps will be more than adequate to interrupt the 1500 amps initial fault current at the transformer secondary. Continuous load current given by the transformer secondary is designated at 135 amps, and the recloser load rating should be somewhat higher. Its minimum trip value should also be sensitive enough to recognize the minimum ultimate faut current gt the end sections of 345 amps.

The range of fuse links that can be selected for protection range between 25 and $80 \mathrm{~T}$ of the applicable EEI-NEiVA \& ANSI designations.

Time-current coordination curves given by a recloser will be on the fast $A$ curve and delayed curves $B, C$, and $E$ as shown in Fig. A2. Fuse links each have minimum melting and maximum clearing curves, with the curves for $\$ 0$ and b5 $T$ fuses shown in Figs. A2 and $A 3$.

Figure A1. Example Analysis of RecloserFuse Time - Current Coordination with Cogeneration Added Later

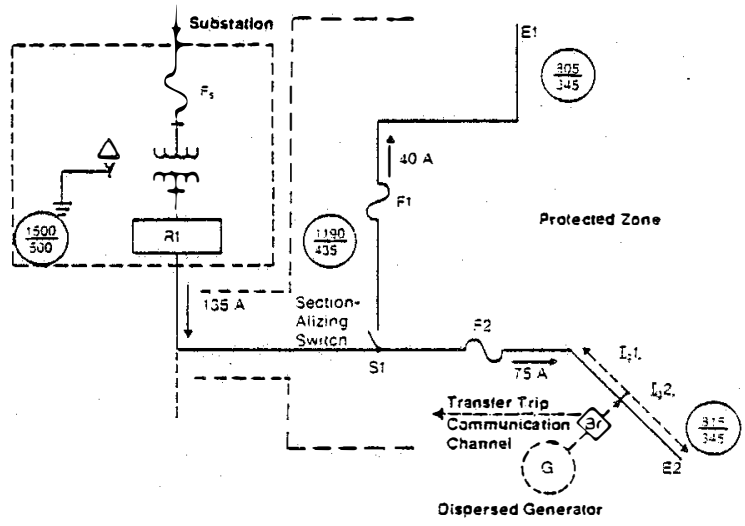


If an operating sequence on the recloser of two fast followed by two slow operations is used, with a reclosing interval of 2 seconds ( 120 cycles), the fast curve must be multiplied by a "K" factor as shown.*

In this particular example coordination with fuses below $40 \mathrm{~T}$ is not possible. For instance, the minimum melting curve of a $30 \mathrm{~T}$ fuse will give a maximum coordinated point of 1000 amps with a "K" factored A curve. This is less than the assumed 1190 amps of initial fault current on feeder SIEl, and the fuse would clear before the recloser had a chance to operate. Thus for temporary faults, the feeder section would be isolated inadvertently.

As shown in Fig. A2 a $40 \mathrm{~T}$ fuse link will give a maximum coordination point of approximately 1450 amps, which is sufficient to Dermit the recloser to clear a fault on its fast $A$ curve. All recloser delayed responses are slower than the maximum clearing curve of a $40 \mathrm{~T}$ fuse, thereby giving a minimum coordination point of 280 amps, in this instance, which will allow the fuse to rupture during the third element of the recloser timing cycle.

Fuse group F2 can employ a $65 \mathrm{~T}$ fuse link for successful coordination under nominal conditions; i.e., dispersed generation operating at peak injection. This will give a maximum coordination point of 2100 amps with a $\mathrm{K}$ factored encloser fast resoonse as shown in Fig. A3. Minimum coordination point for responses $B, C$, and $E$ is 280 amps, but $B$ is considered marginal because of its close proximity to the $65 \mathrm{~T}$ maximum clearing curve in the region of the minimum coordination point.

Curve B will offer a minlmum coordination point of 1350 amps. For fault currents below 1350 amps the $65 \mathrm{~T}$ fuse will clear the fault during the third recloser operation, but for a fault current above 1350 amps, the recloser will clear the fault on the $D$ response and will lock permanently (bolted faults).

This would have the effect of de-energizing the whole system, whereas only the branch feeder on which the fault occurred needs to be isolated.

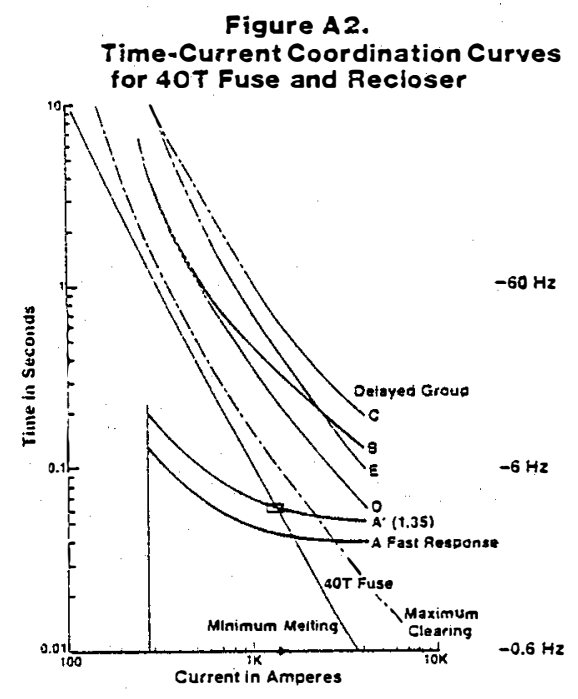

*"K" factor, sometimes called multiplying factor, is used to allow time between the clearing time of a recloser fastcurve $A$ and the melting time of a fuse to prevent damage of fatigue to a fuse link. The magnituce of the multiplying iactors varies with ine iumeer of iasi sperations dnd reclosing time intervals between iast operations; Eig. At shows an example.

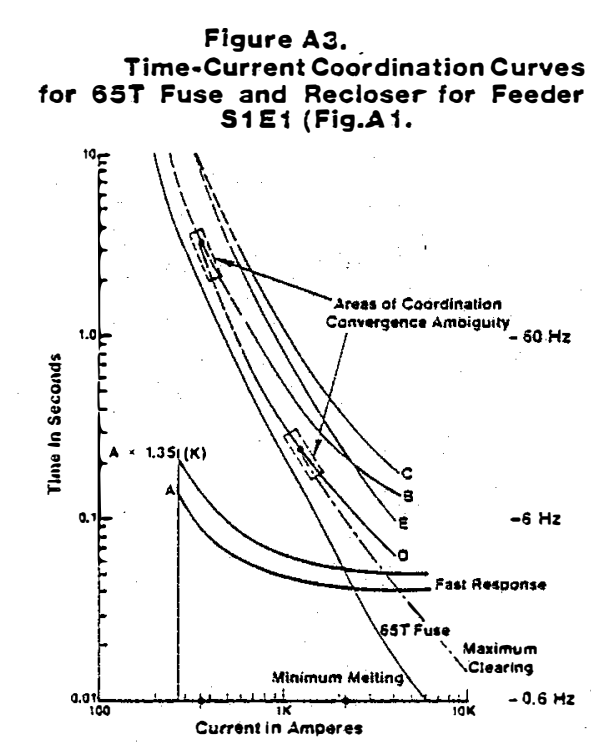

The choice between the $C$ or $E$ responses will not affect the coordination under a given set of conditions, but curve $C$ will provide a greater margin of load-side fuse coordination because of its longer timing. However, there could be problems with source-side coordination.

Now consider the two scenarios with variable dispersed generation. Normally known and stable fault currents are necessary to achieve ef fective coordination. Depending upon the level of penetration, this will not be the case with wind and photovoltaic energy systems added, and thereby complicating the issue.

Residential and intermediate load renewable energy installations ranging from $10 \mathrm{~kW}$ to $100 \mathrm{~kW}$ capacity will invariably feed into a "stiff" low impedance utility voltage source, which will fix the operating voltage of the intertie. The dispersed source will provide power and energy at that voltage to the electrical transmission and distribution system.

A $100-\mathrm{kW}$ photovoltaic installation, perhaps serving a shopping center, would inject between 400 and 500 amps into the system at 240 volts, depending upon relative voltage phasor conditions, power factor, and coupling transformer turns ratio. Transformer turns ratio in the future for photovoltaic systems is liable to be reduced as PV array field voltages increase to reduce $I^{2} R$ losses in the array de field wiring. Thus, currents of the above magnitudes and higher could be evident.

Because of diurnal effects, the injected current will be modulated with a daily cosine function; this, of course, is predictable, as is the PY array short-circuit current, at about $120 \%$ of the current at maximum power operating point on the current/voltage performance curve of the array.

\section{Figure A4. Typical Operation of Recloser}

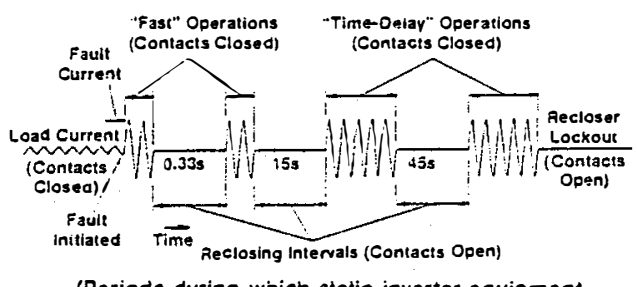

(Periods during which static inverter equipment ean oecome unsyncrionizea)

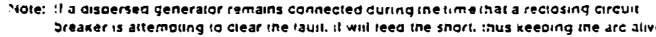


However, what cannot be predicted with any degree of certainty will be the effects upon output current of scudding partial cloud cover passing over the PV array fields, and wind gusts that are not compensated for in a wind energy system.

The overall effect of such current variability on protection coordination could be to create ambiguous and variable timecurrent relationships, which will affect the coordination in a dynamic and probably detrimental way, because the protection schemes currently employed are essentially static. The effects could be particularly pronounced in the situation discussed here, where areas of coordination convergence ambiguity exist as shown in Fig. A3.
The modularity characteristics of wind and photovoltaic energy systems, giving them ideal add-on features, will impact relaying coordination unless proper planning is undertaken.

Under the conditions noted above, a case could be made for some level of real-time precognition of dispersed generation status, such that relay and fuse sensitivities and selection may be dynamically adjusted in their fauit current characteristics to allow maximum protection of network equipment. This will aiso improve service reliability and enhance the safety of linesmen. 